\title{
Bio-Based Aromatic Polyesters from a Novel Bicyclic Diol Derived from D-Mannitol
}

\author{
C. Lavilla, ${ }^{\dagger}$ A. Martínez de Ilarduya,$^{\dagger}$ A. Alla, ${ }^{\dagger}$ M. G. García-Martín ${ }^{\ddagger}$ J. A. Galbis, $^{\dagger}$ and S. Muñoz-Guerra* ${ }^{\dagger}{ }^{\dagger}$ \\ ${ }^{\dagger}$ Departament d’Enginyeria Química, Universitat Politècnica de Catalunya, ETSEIB, Diagonal 647, 08028 Barcelona, Spain \\ ‡Departamento de Química Orgánica y Farmacéutica, Universidad de Sevilla, Profesor García González 2, 41012 Sevilla, Spain
}

Supporting Information

ABSTRACT: 2,4:3,5-Di-O-methylene-D-mannitol, abbreviated as Manx, is a D-mannitol-derived compound with the secondary hydroxyl groups acetalized with formaldehyde. The bicyclic structure of Manx consists of two fused 1,3-dioxane rings, with two primary hydroxyl groups standing free for reaction. A homopolyester made of Manx and dimethyl terephthalate as well as a set of copolyesters of poly(butylene terephthalate) (PBT) in which 1,4-butanediol was replaced by Manx up to $50 \%$ were synthesized and characterized. The polyesters had $M_{\mathrm{w}}$ in the $30000-52000 \mathrm{~g} \mathrm{~mol}^{-1}$ range and a random microstructure and were thermally stable up to nearly $370{ }^{\circ} \mathrm{C}$. They displayed outstanding high $T_{\mathrm{g}}$ with values from 55 to $137^{\circ} \mathrm{C}$ which steadily increased with the content in Manx. Copolyesters containing up to $40 \%$ of Manx were semicrystalline and adopted the crystal structure of PBT. Their stressstrain parameters were sensitively affected by the presence of carbohydrate-based units with elongation at break decreasing but tensile strength and elastic moduli steadily increasing with the degree of replacement.

\section{INTRODUCTION}

Bio-based polymers are nowadays attracting a great deal of interest, not only for their potential to reduce the utilization of petrochemicals but also for increasing the added-value of agriculture products and wastes. ${ }^{1-4}$ Carbohydrates constitute an interesting renewable source for being used as polymer building blocks; they are the most abundant type of biomass feedstock, and they are found in a very rich variety of structures displaying great stereochemical diversity. However, they possess an excess of functional groups that upon polycondensation would lead to undesirable cross-linking reactions unless special precautions are taken. Although some linear polyesters have been synthesized using carbohydrate-based monomers bearing free hydroxyl groups, ${ }^{5,6}$ most syntheses have been carried out with derivatives in which the exceeding functional groups have been appropriately protected. ${ }^{7-10}$

Among carbohydrate-derived monomers, those with a cyclic structure have achieved a privileged position because, in addition to their natural origin, they are able to provide polycondensates with improved properties, especially those related to polymer chain stiffness, as it is the case of the glass transition temperature. A high $T_{g}$ is nowadays a greatly appreciated property in polyesters that are addressed to packaging under heating or to the manufacture of containers for pressurized gaseous beverages. Thus, 2,5-furandicarboxylic acid has been reported as a potential alternative to replace terephthalic acid for the preparation of aromatic polyesters based on renewable sources. ${ }^{11,12}$ 1,4:3,6-Dianhydro-D-glucitol, known as isosorbide, which is prepared by dehydration of Dglucose coming from cereal starch, is the only bicyclic carbohydrate-based monomer industrially available today. Isosorbide and other less accessible dianhydrohexitols derivatives are receiving recently a great deal of attention as building blocks for the synthesis of aromatic copolyesters with increased $T_{\mathrm{g}}{ }^{13-15}$ The two hydroxyl groups of isosorbide are secondary, and due to their different spatial position in the molecule, they display different reactivity. These features seriously hamper the polycondensation reaction in the melt, so isosorbide polyesters obtained by this method display rather limited molecular weights. ${ }^{16,17}$ Another type of carbohydrate-based bicyclic monomer is that obtained by internal acetalization, which has been shown to be very suitable to prepare polyesters by polycondensation in the melt since they are able to react at a rate similar to that of other acyclic conventional monomers. $^{18-20}$

In this work we present a new bicyclic carbohydrate-based monomer useful for the preparation of linear polycondensates. 2,4:3,5-Di-O-methylene-D-mannitol, abbreviated as Manx, is a D-mannitol-derived compound with the secondary hydroxyl groups acetalized with formaldehyde. A set of copolyesters of poly(butylene terephthalate) (PBT) in which the 1,4butanediol has been replaced by Manx have been synthesized

Received: June 27, 2012

Revised: September 10, 2012

Published: October 10, 2012 
and characterized. PBT is a well-known thermoplastic aromatic polyester, with a melting temperature near $225^{\circ} \mathrm{C}$ and a glass transition temperature around $30^{\circ} \mathrm{C}$, which is used in a wide variety of engineering applications. ${ }^{21}$ Nevertheless, despite being innocuous for humans, PBT and other aromatic polyesters are considered not to be environmentally friendly materials due to their nonrenewable origin. ${ }^{22}$ In this work special attention is paid to study the effect of the introduction of renewable Manx on the glass transition temperature, thermal stability, and crystallizability of the resulting PBT copolyesters because of the relevance that these properties have not only for the technical use of PBT but also for the potential application that this novel carbohydrate-based monomer may have in the synthesis of other polycondensates. Contrary to isosorbide, the two hydroxyl groups of Manx remaining free for reaction are primary, and since Manx possess a 2-fold axis of symmetry, they display the same reactivity. Moreover, the use of Manx as polycondensation monomer leads to regioregular polymer chains, provided that it is made to react with nondirectional monomers.

\section{EXPERIMENTAL SECTION}

Materials. The reagents D-mannitol (ACS reagent grade), benzoyl chloride (99+\%), paraformaldehyde (95\%), 1,4-butanediol (99\%), and dimethyl terephthalate $(99+\%)$ and the catalyst dibutyl tin oxide (DBTO, 98\%) were purchased from Sigma-Aldrich. Solvents used for purification and characterization were purchased from Panreac, and they all were of either technical or high-purity grade. All the reagents and solvents were used as received without further purification.

General Methods. ${ }^{1} \mathrm{H}$ and ${ }^{13} \mathrm{C}$ NMR spectra were recorded on a Bruker AMX-300 spectrometer at $25.0^{\circ} \mathrm{C}$ operating at 300.1 and 75.5 $\mathrm{MHz}$, respectively. Samples were dissolved in either deuterated chloroform, deuterated dimethyl sulfoxide, or a mixture of deuterated chloroform and trifluoroacetic acid (9:1), and spectra were internally referenced to tetramethylsilane (TMS). About 10 and $50 \mathrm{mg}$ of sample dissolved in $1 \mathrm{~mL}$ of solvent were used for ${ }^{1} \mathrm{H}$ and ${ }^{13} \mathrm{C} N M R$, respectively. Sixty-four scans were acquired for ${ }^{1} \mathrm{H}$ and $1000-10000$ for ${ }^{13} \mathrm{C}$ with $32 \mathrm{~K}$ and $64 \mathrm{~K}$ data points as well as relaxation delays of 1 and $2 \mathrm{~s}$, respectively. For conformational studies ${ }^{1} \mathrm{H}$ NMR spectra were recorded from 60 to $-60^{\circ} \mathrm{C}$ in the NMR spectrometer equipped with a variable-temperature unit. Temperatures were selected at $20^{\circ} \mathrm{C}$ interval. For each temperature the sample was held for $10 \mathrm{~min}$ to reach thermal equilibrium. 2D NOE spectrum (NOESY) was recorded at a fixed temperature $(T=298.1 \mathrm{~K})$ with a standard pulse sequence (noesytp) with a mixing time of $2 \mathrm{~s}$ over a sweep width of $1397 \mathrm{~Hz}$ using 2048 data points in the $t_{2}$ dimension and 256 increments in the $t_{1}$ dimension. The repetition delay was $2 \mathrm{~s}$, and $256 \mathrm{scans}$ were collected for each $t_{1}$ increment. ${ }^{1} \mathrm{H}$ NMR simulated spectra were obtained with SpinWorks 3.1.8 program (Kirk Marat, University of Manitoba). Intrinsic viscosities of polymers dissolved in dichloroacetic acid were measured in an Ubbelohde viscosimeter thermostated at $25.0 \pm 0.1{ }^{\circ} \mathrm{C}$. Gel permeation chromatograms were acquired at 35.0 ${ }^{\circ} \mathrm{C}$ using a Waters equipment provided with a refraction index detector. The samples were chromatographed with $0.05 \mathrm{M}$ sodium trifluoroacetate--hexafluoroisopropanol (NaTFA-HFIP) using a polystyrene-divinylbenzene packed linear column with a flow rate of $0.5 \mathrm{~mL} \mathrm{~min}{ }^{-1}$. Chromatograms were calibrated against poly(methyl methacrylate) (PMMA) monodisperse standards. The thermal behavior of polyesters was examined by DSC using a PerkinElmer DSC Pyris 1 . DSC data were obtained from 3 to $5 \mathrm{mg}$ samples at heating/cooling rates of $10^{\circ} \mathrm{C} \mathrm{min}-1$ under a nitrogen flow of $20 \mathrm{~mL}$ $\mathrm{min}^{-1}$. Indium and zinc were used as standards for temperature and enthalpy calibration. The glass-transition temperatures were determined at a heating rate of $20{ }^{\circ} \mathrm{C} \mathrm{min}^{-1}$ from rapidly melt-quenched polymer samples. The treatment of the samples for isothermal crystallization experiments was the following: the thermal history was removed by heating the sample up to $250{ }^{\circ} \mathrm{C}$ and left at this temperature for $5 \mathrm{~min}$, and then it was cooled at $20{ }^{\circ} \mathrm{C} \mathrm{min}-1$ to the selected crystallization temperature, where it was left to crystallize until saturation. For morphological study, isothermal crystallizations under the same conditions were carried out in an Olympus BX51 polarizing optical microscope coupled to a THMS LINKAM heating plate and a cooling system LNP (liquid nitrogen pump). Thermogravimetric analyses were performed under a nitrogen flow of $20 \mathrm{~mL} \mathrm{~min}^{-1}$ at a heating rate of $10^{\circ} \mathrm{C} \mathrm{min}^{-1}$, within a temperature range of $30-600{ }^{\circ} \mathrm{C}$, using a PerkinElmer TGA 6 equipment. Sample weights of about 10$15 \mathrm{mg}$ were used in these experiments. Films for mechanical testing measurements were prepared with a thickness of $\sim 200 \mu \mathrm{m}$ by casting from solution $\left(100 \mathrm{~g} \mathrm{~L}^{-1}\right)$ in either chloroform or a mixture of chloroform and hexafluoroisopropanol (5:1); the films were then cut into strips with a width of $3 \mathrm{~mm}$ while the distance between testing marks was $10 \mathrm{~mm}$. The tensile strength, elongation at break, and Young's modulus were measured at a stretching rate of $30 \mathrm{~mm} \mathrm{~min}^{-1}$ at $23{ }^{\circ} \mathrm{C}$ on a Zwick $2.5 / \mathrm{TN} 1 \mathrm{~S}$ testing machine coupled with a compressor Dalbe DR 150. X-ray diffraction patterns were recorded on the PANalytical X'Pert PRO MPD $\theta / \theta$ diffractometer using the $\mathrm{Cu}$ $\mathrm{K} \alpha$ radiation of wavelength $0.1542 \mathrm{~nm}$ from powdered samples coming directly from synthesis.

Monomer Synthesis. 1,6-Di-O-benzoyl-D-mannitol. A solution of $28.1 \mathrm{~g}$ of benzoyl chloride $(200 \mathrm{mmol})$ in dry pyridine $(70 \mathrm{~mL})$ was added dropwise to a dispersion of $36.4 \mathrm{~g}$ of $\mathrm{D}$-mannitol $(200 \mathrm{mmol})$ in $70 \mathrm{~mL}$ of dry pyridine. The mixture was stirred at room temperature for $5 \mathrm{~h}$ and then poured into ice-water. The precipitated solid was filtered, washed with cold water and with chloroform, dried, and recrystallized from ethanol. Yield: $36 \%$; mp $189-193{ }^{\circ} \mathrm{C}\left[\right.$ lit. $^{23} 188-$ $\left.192{ }^{\circ} \mathrm{C}\right] .{ }^{1} \mathrm{H}$ NMR $(300.1 \mathrm{MHz}, \mathrm{DMSO}), \delta$ (ppm): 8.1 (m, 4H, $o-$ $\mathrm{ArH}$ ), $7.6(\mathrm{~m}, 2 \mathrm{H}, p-\mathrm{ArH}), 7.5$ (m, 4H, m-ArH), 5.1 (bs, $2 \mathrm{H}, \mathrm{OH})$, 4.7-4.3 (m, 6H, OCH $2, \mathrm{OH}), 3.9\left(\mathrm{~m}, 2 \mathrm{H}, \mathrm{CH}_{2} \mathrm{CHOH}, 3.7(\mathrm{~d}, 2 \mathrm{H}\right.$, $\left.\mathrm{CH}_{2} \mathrm{CHOHCHOH}\right) .{ }^{13} \mathrm{C}$ NMR (75.5 MHz, DMSO), $\delta$ (ppm): 166.0 (CO), 133.1, 130.1, 129.3, 128.6, 69.1, 68.3, 67.7.

1,6-Di-O-benzoyl-2,4:3,5-di-O-methylene-D-mannitol. To a mixture of $28.0 \mathrm{~g}$ of 1,6-di-O-benzoyl-D-mannitol $(72 \mathrm{mmol})$ and $28.0 \mathrm{~g}$ of paraformaldehyde $(930 \mathrm{mmol}), 22 \mathrm{~mL}$ of sulfuric acid $96 \%$ was added dropwise, and the mixture was stirred for $3 \mathrm{~h}$ at room temperature. The reaction mixture was then repeatedly extracted with chloroform. The combined organic layers were washed with ammonia $(12 \% \mathrm{w} / \mathrm{w})$ and water and dried over anhydrous sodium sulfate. The solution was evaporated to a solid residue, which was recrystallized from ethanol. Yield: 52\%; mp 121-122 ${ }^{\circ} \mathrm{C}$ [lit. ${ }^{24} 121{ }^{\circ} \mathrm{C}$ ]. ${ }^{1} \mathrm{H}$ NMR $(300.1 \mathrm{MHz}$, $\left.\mathrm{CDCl}_{3}\right), \delta(\mathrm{ppm}): 8.1(\mathrm{~m}, 4 \mathrm{H}, o-\mathrm{ArH}), 7.6(\mathrm{~m}, 2 \mathrm{H}, p-\mathrm{ArH}), 7.4(\mathrm{~m}$, $4 \mathrm{H}, m-\mathrm{ArH}), 5.0-4.8\left(\mathrm{dd}, 4 \mathrm{H}, \mathrm{OCH}_{2} \mathrm{O}\right), 4.8-4.3\left(\mathrm{~m}, 4 \mathrm{H}, \mathrm{COOCH}_{2}\right)$, $4.4\left(\mathrm{~m}, 2 \mathrm{H}, \mathrm{OCH}_{2} \mathrm{CH}\right), 4.2\left(\mathrm{~m}, 2 \mathrm{H}, \mathrm{OCH}_{2} \mathrm{CHCH}\right) .{ }^{13} \mathrm{C}$ NMR $(75.5$ $\left.\mathrm{MHz}, \mathrm{CDCl}_{3}\right), \delta(\mathrm{ppm}): 166.3(\mathrm{CO}), 133.2,129.7,129.6,128.4,88.5$, 71.1, 66.7, 63.7 .

2,4:3,5-Di-O-methylene-D-mannitol. A dispersion of $15.5 \mathrm{~g}$ of 1,6di-O-benzoyl-2,4:3,5-di-O-methylene-D-mannitol $(37 \mathrm{mmol})$ in 200 $\mathrm{mL}$ of dry methanol was stirred overnight with a small piece of sodium. The solution was treated with cation exchange resin, the resin was filtered, and the filtrate was concentrated to dryness. The resulting semisolid residue was washed with diethyl ether and recrystallized from ethanol. Yield: $72 \%$; mp $139-140{ }^{\circ} \mathrm{C}\left[\right.$ lit. $\left.^{25} 139{ }^{\circ} \mathrm{C}\right] .{ }^{1} \mathrm{H}$ NMR $\left(300.1 \mathrm{MHz}, \mathrm{CDCl}_{3}\right), \delta(\mathrm{ppm}): 5.0-4.8\left(\mathrm{dd}, 4 \mathrm{H}, \mathrm{OCH}_{2} \mathrm{O}\right), 4.2(\mathrm{~m}$, $\left.2 \mathrm{H}, \mathrm{HOCH}_{2} \mathrm{CH}\right), 4.1\left(\mathrm{~m}, 2 \mathrm{H}, \mathrm{HOCH}_{2} \mathrm{CHCH}\right), 4.0-3.7(\mathrm{~m}, 4 \mathrm{H}$, $\left.\mathrm{HOCH}_{2}\right), 1.9$ (bs, $\left.2 \mathrm{H}, \mathrm{OH}\right) .{ }^{13} \mathrm{C} \mathrm{NMR}\left(75.5 \mathrm{MHz}, \mathrm{CDCl}_{3}\right), \delta$ (ppm): 87.2, 73.5, 65.8, 59.6

Polymer Synthesis. $\mathrm{PB}_{x} \mathrm{Manx}_{y} \mathrm{~T}$ copolyesters were obtained from a mixture of 1,4-butanediol, 2,4:3,5-di-O-methylene-D-mannitol, and dimethyl terephthalate with the selected composition. PBT and PManxT homopolyesters were obtained by reacting dimethyl terephthalate with 1,4-butanediol and 2,4:3,5-di-O-methylene-Dmannitol, respectively. The reactions were performed in a threenecked, cylindrical-bottom flask equipped with a mechanical stirrer, a nitrogen inlet, and a vacuum distillation outlet. An excess of diol mixture to dimethyl terephthalate was used, and dibutyl tin oxide (DBTO, 0.6\% molar respect to monomers) was the catalyst of choice. The apparatus was vented with nitrogen several times at room temperature in order to remove air and avoid oxidation during the 
polymerization. Transesterification reactions were carried out under a low nitrogen flow at the selected temperature. Polycondensation reactions were left to proceed at the selected temperature under a 0.03-0.06 mbar vacuum. Then, the reaction mixture was cooled to room temperature, and the atmospheric pressure was recovered with nitrogen to prevent degradation. The resulting polymers were dissolved in chloroform or in a mixture of chloroform and trifluoroacetic acid (9:1) and precipitated in excess of methanol in order to remove unreacted monomers and formed oligomers. Finally, the polymer was collected by filtration, extensively washed with methanol, and dried under vacuum.

PBT Homopolyester. $60 \%$ molar excess of 1,4-butanediol to dimethyl terephthalate. Transesterification reactions at $180{ }^{\circ} \mathrm{C}$ for 1 $\mathrm{h}$, at $200{ }^{\circ} \mathrm{C}$ for $1 \mathrm{~h}$, and at $240{ }^{\circ} \mathrm{C}$ for $0.5 \mathrm{~h}$ under a low nitrogen flow. Polycondensation reactions at $260^{\circ} \mathrm{C}$ for $2 \mathrm{~h}$ under a $0.03-0.06 \mathrm{mbar}$ vacuum. ${ }^{1} \mathrm{H} \mathrm{NMR}\left(300.1 \mathrm{MHz}, \mathrm{CDCl}_{3} / \mathrm{TFA}\right), \delta(\mathrm{ppm}): 8.13$ (s, $4 \mathrm{H}$, $\mathrm{ArH}), 4.50\left(\mathrm{t}, 4 \mathrm{H} \mathrm{OCH} \mathrm{CH}_{2}\right), 2.02\left(\mathrm{t}, 4 \mathrm{H}, \mathrm{OCH}_{2} \mathrm{CH}_{2}\right) .{ }^{13} \mathrm{C} \mathrm{NMR}$ (75.5 MHz, $\left.\mathrm{CDCl}_{3} / \mathrm{TFA}\right), \delta$ (ppm): 168.0 (CO), 133.7, 129.9, 66.2, 25.1.

PManxT Homopolyester. 5\% molar excess of 2,4:3,5-di-Omethylene-D-mannitol to dimethyl terephthalate. Transesterification reactions at $160{ }^{\circ} \mathrm{C}$ for $1 \mathrm{~h}$ and at $180{ }^{\circ} \mathrm{C}$ for $2 \mathrm{~h}$ under a low nitrogen flow. Polycondensation reactions at $180{ }^{\circ} \mathrm{C}$ for $5 \mathrm{~h}$ under a $0.03-0.06$ mbar vacuum. ${ }^{1} \mathrm{H}$ NMR (300.1 MHz, $\left.\mathrm{CDCl}_{3} / \mathrm{TFA}\right), \delta(\mathrm{ppm}): 8.1$ (s, $4 \mathrm{H}, \mathrm{Ar}-\mathrm{H}), 5.2-5.0\left(\mathrm{~m}, 4 \mathrm{H}, \mathrm{OCH}_{2} \mathrm{O}\right), 4.9-4.5\left(\mathrm{~m}, 4 \mathrm{H}, \mathrm{OCH}_{2} \mathrm{CH}\right)$, $4.7\left(\mathrm{~m}, 2 \mathrm{H}, \mathrm{OCH}_{2} \mathrm{CH}\right), 4.3\left(\mathrm{~m}, 2 \mathrm{H}, \mathrm{OCH}_{2} \mathrm{CHCH}\right) .{ }^{13} \mathrm{C} \mathrm{NMR}(75.5$ $\left.\mathrm{MHz}, \mathrm{CDCl}_{3} / \mathrm{TFA}\right), \delta$ (ppm): 167.5 (CO), 133.5, 130.3, 88.6, 71.4, 66.7, 64.4.

$P B_{x} M_{\text {Mnx }} T$ Copolyesters. The copolyesters were obtained by a similar procedure, with polymerization conditions slightly differing for each composition feed.

$P B_{90}$ Manx ${ }_{10} T$ and $P B_{80}$ Manx $_{20}$ T. 5\% molar excess of the diol mixture to dimethyl terephthalate. Transesterification reactions at 160 ${ }^{\circ} \mathrm{C}$ for $1 \mathrm{~h}$, at $200{ }^{\circ} \mathrm{C}$ for $1 \mathrm{~h}$, and at $240{ }^{\circ} \mathrm{C}$ for $0.5 \mathrm{~h}$ under a low nitrogen flow. Polycondensation reactions at $240{ }^{\circ} \mathrm{C}$ for $2.5 \mathrm{~h}$ under a 0.03-0.06 mbar vacuum.

$P B_{70}$ Manx $_{30}$ T. 5\% molar excess of the diol mixture to dimethyl terephthalate. Transesterification reactions at $160^{\circ} \mathrm{C}$ for $1 \mathrm{~h}$, at $200{ }^{\circ} \mathrm{C}$ for $1 \mathrm{~h}$, and at $230{ }^{\circ} \mathrm{C}$ for $0.5 \mathrm{~h}$ under a low nitrogen flow. Polycondensation reactions at $230{ }^{\circ} \mathrm{C}$ for $3 \mathrm{~h}$ under a $0.03-0.06 \mathrm{mbar}$ vacuum.

$P B_{60}$ Manx $_{40}$ T. 5\% molar excess of the diol mixture to dimethyl terephthalate. Transesterification reactions at $160{ }^{\circ} \mathrm{C}$ for $1 \mathrm{~h}$, at $200{ }^{\circ} \mathrm{C}$ for $1 \mathrm{~h}$, and at $220{ }^{\circ} \mathrm{C}$ for $0.5 \mathrm{~h}$ under a low nitrogen flow. Polycondensation reactions at $220{ }^{\circ} \mathrm{C}$ for $3.5 \mathrm{~h}$ under a $0.03-0.06$ mbar vacuum.

$P B_{50}$ Manx $_{50}$ T. 5\% molar excess of the diol mixture to dimethyl terephthalate. Transesterification reactions at $160{ }^{\circ} \mathrm{C}$ for $1 \mathrm{~h}$, at $200{ }^{\circ} \mathrm{C}$ for $1 \mathrm{~h}$, and at $210{ }^{\circ} \mathrm{C}$ for $0.5 \mathrm{~h}$ under a low nitrogen flow. Polycondensation reactions at $210^{\circ} \mathrm{C}$ for $4 \mathrm{~h}$ under a $0.03-0.06 \mathrm{mbar}$ vacuum.

NMR Characterization of $P B_{x}$ Manx $_{y} T$ Copolyesters . ${ }^{1} \mathrm{H}$ NMR (300.1 MHz, $\left.\mathrm{CDCl}_{3} / \mathrm{TFA}\right), \delta(\mathrm{ppm}): 8.1(\mathrm{~s}, 4 \mathrm{H}, \mathrm{Ar}-\mathrm{H}), 5.2-5.0(\mathrm{~m}$, $\left.\mathrm{y} \cdot 4 \mathrm{H}, \mathrm{OCH}_{2} \mathrm{O}\right), 4.9-4.5\left(\mathrm{~m}, \mathrm{y} \cdot 4 \mathrm{H}, \mathrm{OCH}_{2} \mathrm{CH}\right), 4.7(\mathrm{~m}, \mathrm{y} \cdot 2 \mathrm{H}$, $\left.\mathrm{OCH}_{2} \mathrm{CH}\right), 4.5\left(\mathrm{t}, \mathrm{x} \cdot 4 \mathrm{H}, \mathrm{OCH}_{2} \mathrm{CH}_{2}\right), 4.3\left(\mathrm{~m}, \mathrm{y} \cdot 2 \mathrm{H}, \mathrm{OCH}_{2} \mathrm{CHCH}\right)$, $2.0\left(\mathrm{t}, \mathrm{x} \cdot 4 \mathrm{H}, \mathrm{OCH}_{2} \mathrm{CH}_{2}\right) .{ }^{13} \mathrm{C} \mathrm{NMR}\left(75.5 \mathrm{MHz}, \mathrm{CDCl}_{3} / \mathrm{TFA}\right), \delta$ (ppm): 168.3 (CO), 167.5 (CO), 134.2-133.3, 130.4, 130.2, 88.6, $71.4,66.7,66.5,64.4,25.4$.

\section{RESULTS AND DISCUSSION}

Monomer Synthesis and Conformation. The bicyclic diol 2,4:3,5-di-O-methylene-D-mannitol (Manx) was prepared from D-mannitol following the chemical synthetic route depicted in Scheme 1. Primary hydroxyl groups of D-mannitol were first protected as benzoyl esters, and then the addition of paraformaldehyde led to cyclic acetalization of the secondary hydroxyl groups in the 2,4:3,5 arrangement with the two fused 1,3-dioxane rings. ${ }^{1} \mathrm{H}$ and ${ }^{13} \mathrm{C}$ NMR spectra of Manx are shown
Scheme 1. Synthesis of 2,4:3,5-Di-O-methylene-D-mannitol

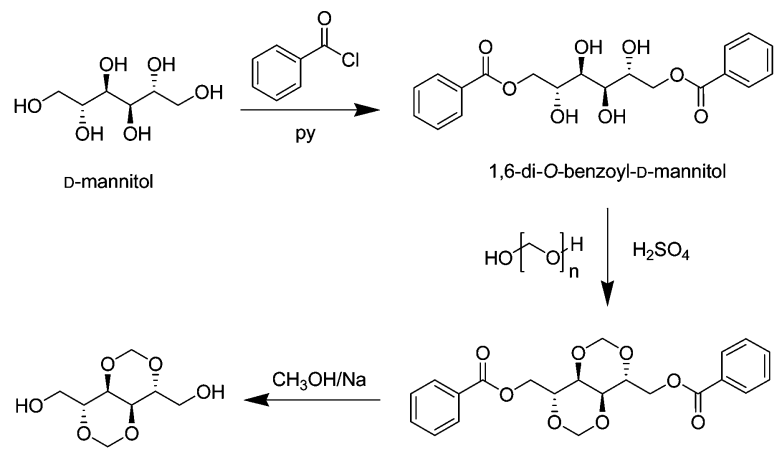

2,4:3,5-di-O-methylene-D-mannitol

1,6-di-O-benzoyl-2,4:3,5-di-O-methylene-D-mannitol

in the Supporting Information and detailed in the Experimental Section. The coupling between the two protons of the methylene acetalic group with a $J=-6.2 \mathrm{~Hz}$ confirms the presence of the two fused six-membered rings and then the $2,4: 3,5$ arrangement of the bicyclic structure. ${ }^{26}$ It should be stressed that the synthesis route used for the preparation of Manx, although effective for the purpose of the work, is not environmentally friendly. Obviously, an alternative synthetic route or an improvement of the existing one will need to be developed to make this monomer of fully practical use and to render benefits to the environment.

This bicyclic diol Manx possesses a 2-fold axis of symmetry, and therefore its two hydroxyl groups will display the same reactivity in the polycondensation reaction producing regioregular polymer chains. Since the two rings are fused, a fairly high degree of rigidity should be in principle expected for Manx although it could be largely relieved if interconversion between possible conformers takes place. The rigidity of the monomer is critical for the preparation of polymers with improved thermal and mechanical properties. To appraise the effect that this novel diol monomer will have on the stiffness of the polyesters thence produced, a conformational analysis of 1,6-di-O-benzoyl2,4:3,5-di-O-methylene-D-mannitol was undertaken. This diester is an adequate model compound for aromatic polyesters and copolyesters made from Manx. The two most probable conformations $^{27}$ for the 2,4:3,5-di-O-methylene-D-manno bicyclic structure are depicted in Scheme 2. In order to assess the

Scheme 2. Preferential Conformers of 1,6-Di-O-benzoyl2,4:3,5-di-O-methylene-D-mannitol

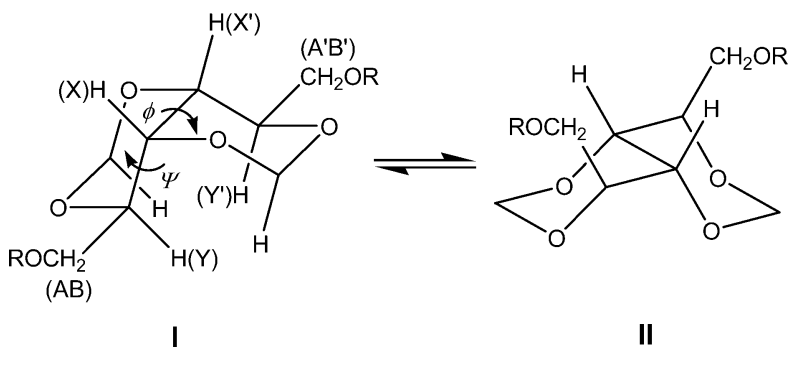

relative preference of Manx for these two conformations, a variable temperature ${ }^{1} \mathrm{H}$ NMR study was carried out in the +60 to $-60{ }^{\circ} \mathrm{C}$ range, and $2 \mathrm{D}-\mathrm{NOESY}$ spectra were recorded at room temperature. In the case that I and II conformers were present, two signals for each proton should appear in the ${ }^{1} \mathrm{H}$ NMR spectra at low temperatures since no interconversion is 
expected to take place under such conditions. On the contrary, single proton signals were observed along the whole interval and the only detected change was an upfield shift of the signals with heating (see Supporting Information). It can be concluded therefore that no conformational interconversion occurs and that only one conformer is present along the whole range of temperatures. The analysis of the coupling constants of the ${ }^{1} \mathrm{H}$ NMR spectra suggested that conformer $\mathbf{I}$ is the preferred one for Manx. In fact, NMR spin simulation using the SpinWorks 3 program provided the spin-spin coupling constants (see

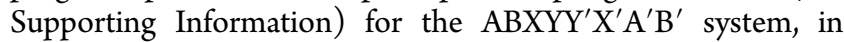
which small long-range couplings between $\mathrm{Y}$ and $\mathrm{X}^{\prime}$ protons were detected. The calculated coupling constants were

$$
\begin{array}{cl}
J_{\mathrm{AB}}=J_{\mathrm{A}^{\prime} \mathrm{B}^{\prime}}=-11.98 \mathrm{~Hz} ; & J_{\mathrm{AY}}=J_{\mathrm{A}^{\prime} \mathrm{Y}^{\prime}}=2.91 \mathrm{~Hz} \\
J_{\mathrm{BY}}=J_{\mathrm{B}^{\prime} \mathrm{Y}^{\prime}}=6.71 \mathrm{~Hz} ; & J_{\mathrm{YY}^{\prime}}=J_{\mathrm{Y}^{\prime} \mathrm{Y}}=5.3 \mathrm{~Hz} \\
J_{\mathrm{YX}}=J_{\mathrm{Y}^{\prime} \mathrm{X}^{\prime}}=8.60 \mathrm{~Hz} ; & J_{\mathrm{YX}^{\prime}}=J_{\mathrm{Y}^{\prime} \mathrm{X}}=-0.58 \mathrm{~Hz}
\end{array}
$$

Applying these coupling constants to the Karplus equation derived for alditols, ${ }^{28,29}$ the torsional angles $\Psi$ and $\Phi$ could be estimated. The values obtained were $160^{\circ}$ and $48^{\circ}$, respectively, which are very close to the angles measured for conformer I but very far from those of conformer II.

The identity of conformer I as the preferred one was strongly supported by 2D NOESY spectrum (Figure 1). As expected for

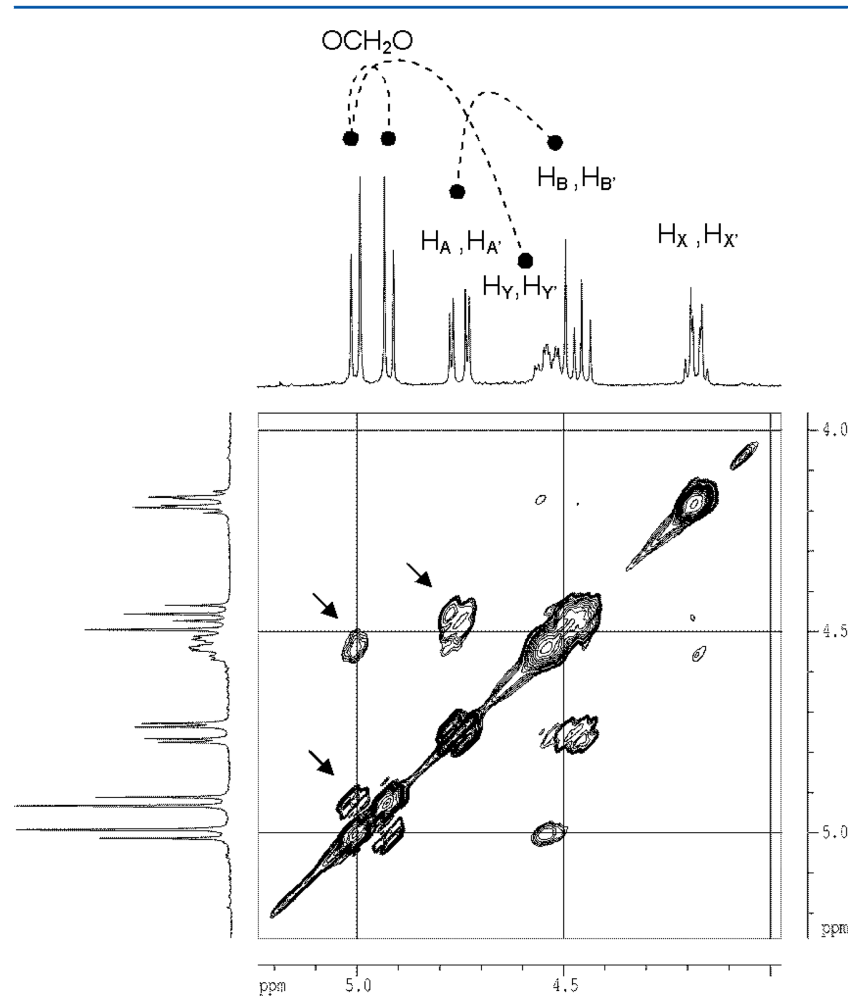

Figure 1. 2D NOESY spectrum of 1,6-di-O-benzoyl-2,4:3,5-di-Omethylene-D-mannitol. Small arrows indicate NOE signals.

conformation I, strong NOE signals were detected for $\mathrm{H}_{\mathrm{Y}}$ and one of the acetal methylene protons, whereas no NOE signals were observed for $\mathrm{H}_{\mathrm{X}}$. In conformation II the short distances between $\mathrm{H}_{\mathrm{X}}$ and one of the protons of the acetal methylene should be reflected in the $2 \mathrm{D}$ spectra with strong NOE signals, which is not the case. It is worthy to note that crystal structure studies on 2,4:3,5-di-O-methylene-D-mannitol-1,6-di-trans-cin- namate $^{30}$ established a conformation in the solid state for the bicyclic unit similar to which is determined in this work. The conclusion derived from this conformational study is that the preferred conformation of Manx is I and that this conformation is well stable; such features will confer to this monomer an enhancing stiffness effect on the polymer chain in which it is inserted.

Polymer Synthesis and Chemical Structure. The polymerizations involving 2,4:3,5-di-O-methylene-D-mannitol were carried out in the total absence of solvents to imitate as far as possible the conditions usually applied in the industrial practice. PManxT homopolyester, from 2,4:3,5-di-O-methylene-D-mannitol and dimethyl terephthalate, as well as $\mathrm{PB}_{x} \mathrm{Manx}_{y} \mathrm{~T}$ copolyesters from 2,4:3,5-di-O-methylene-D-mannitol, 1,4-butanediol, and dimethyl terephthalate, were prepared by a two-step melt-polycondensation process using DBTO as catalyst (Scheme 3). For comparison purposes, the parent PBT

Scheme 3. Polymerization Reactions Leading to $\mathrm{PB}_{x} \mathrm{Manx} y$ Copolyesters

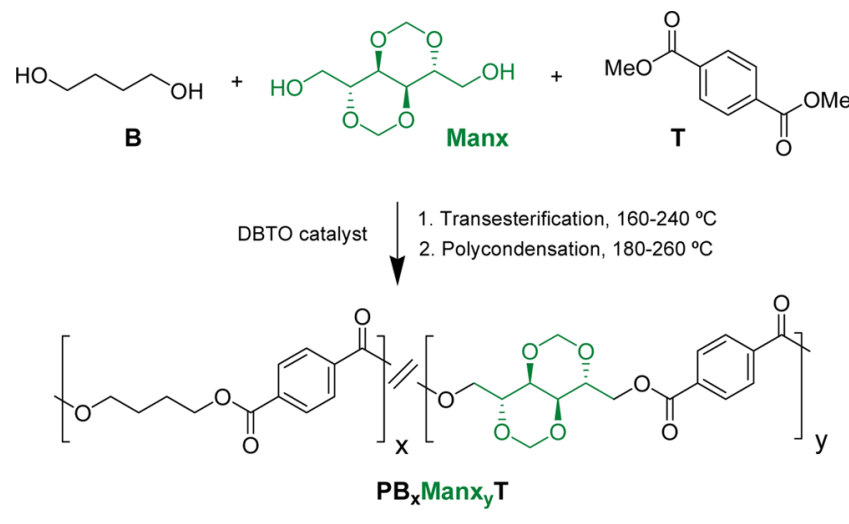

homopolyester was obtained from 1,4-butanediol and dimethyl terephthalate using the same polycondensation procedure. In the preparation of $\mathrm{PB}_{x} \mathrm{Manx}_{y} \mathrm{~T}$ copolyesters, the incorporation of the diols into the copolyesters was accurately controlled by using a 5\% molar excess of the diol mixture to dimethyl terephthalate and by initiating transesterification reactions at mild temperature to prevent volatilization of diols. Temperature was progressively increased to avoid crystallization of oligomers, and polycondensation reactions were performed at temperatures between 210 and $240{ }^{\circ} \mathrm{C}$ and under vacuum to facilitate the removal of volatile byproducts; lower temperatures and longer reaction times were used in copolyesters with higher contents in Manx to minimize the decomposition of this sugar compound. When polymerizations were ended, the reaction mixtures were dissolved either in chloroform or in a mixture of chloroform and trifluoroacetic acid and precipitated in methanol to obtain the polymers in yields close to $85-90 \%$. The synthesis results obtained for sugar-based PManxT homopolyester and $\mathrm{PB}_{x} \mathrm{Manx}_{y} \mathrm{~T}$ copolyesters are gathered in Table 1 together with data for the parent PBT homopolyester.

The precipitated $\mathrm{PB}_{x} \mathrm{Manx}_{y} \mathrm{~T}$ copolyesters were obtained with intrinsic viscosities between 0.8 and $1.2 \mathrm{dL} \mathrm{g}^{-1}$, weightaverage molecular weights confined in the $38000-52000 \mathrm{~g}$ $\mathrm{mol}^{-1}$ interval, and dispersities in the 2.3-2.5 range. Molecular weights of $\mathrm{PB}_{x} \mathrm{Manx}_{y} \mathrm{~T}$ copolyesters slightly decay with the content in Manx, in accordance with the values observed for PManxT homopolyester. The GPC analysis of the reaction product (without being subjected to any treatment) afforded 
Table 1. Molar Composition, Molecular Weight, and Microstructure of $\mathbf{P B}_{x} M a n x_{y} T$ Copolyesters

\begin{tabular}{|c|c|c|c|c|c|c|c|c|c|c|c|c|c|c|c|}
\hline \multirow[b]{3}{*}{ copolyester } & \multirow[b]{3}{*}{$\begin{array}{c}\text { yield } \\
(\%)\end{array}$} & \multicolumn{4}{|c|}{ molar composition } & \multirow{2}{*}{\multicolumn{4}{|c|}{ molecular weight }} & \multicolumn{6}{|c|}{ microstructure } \\
\hline & & \multicolumn{2}{|c|}{ feed } & \multicolumn{2}{|c|}{ copolyester $^{a}$} & & & & & \multicolumn{3}{|c|}{ dyads } & \multicolumn{2}{|c|}{$\begin{array}{l}\text { number- } \\
\text { average } \\
\text { sequence } \\
\text { lengths }\end{array}$} & \multirow{2}{*}{$\frac{\text { randomness }^{d}}{R}$} \\
\hline & & $X_{\mathrm{B}}$ & $X_{\text {Manx }}$ & $X_{\mathrm{B}}$ & $X_{\text {Manx }}$ & {$[\eta]^{b}$} & $M_{\mathrm{n}}{ }^{c}$ & $M_{\mathrm{w}}{ }^{c}$ & $D^{c}$ & BB & $\begin{array}{c}\text { BManx/ } \\
\text { ManxB }\end{array}$ & ManxManx & $n_{\mathrm{B}}$ & $n_{\text {Manx }}$ & \\
\hline PBT & 90 & 100 & 0 & 100 & 0 & 0.93 & $\begin{array}{c}17100 \\
(11800)\end{array}$ & $\begin{array}{c}41300 \\
(40500)\end{array}$ & $\begin{array}{c}2.4 \\
(3.4)\end{array}$ & & & & & & \\
\hline $\mathrm{PB}_{90} \mathrm{Manx}_{10} \mathrm{~T}$ & 86 & 90 & 10 & 91.0 & 9.0 & 1.18 & $\begin{array}{c}20300 \\
(14200)\end{array}$ & $\begin{array}{c}51200 \\
(50800)\end{array}$ & $\begin{array}{c}2.5 \\
(3.6)\end{array}$ & 75.6 & 21.7 & 2.7 & 8.0 & 1.3 & 0.92 \\
\hline $\mathrm{PB}_{80} \mathrm{Manx}_{20} \mathrm{~T}$ & 87 & 80 & 20 & 80.3 & 19.7 & 0.84 & $\begin{array}{c}16500 \\
(11500)\end{array}$ & $\begin{array}{c}41000 \\
(40200)\end{array}$ & $\begin{array}{c}2.5 \\
(3.5)\end{array}$ & 59.9 & 34.0 & 6.1 & 4.5 & 1.4 & 0.96 \\
\hline $\mathrm{PB}_{70} \mathrm{Manx}_{30} \mathrm{~T}$ & 86 & 70 & 30 & 69.2 & 30.8 & 0.75 & $\begin{array}{c}16600 \\
(10400)\end{array}$ & $\begin{array}{c}38500 \\
(37900)\end{array}$ & $\begin{array}{c}2.3 \\
(3.6)\end{array}$ & 44.9 & 44.0 & 11.1 & 3.0 & 1.5 & 0.99 \\
\hline $\mathrm{PB}_{60} \mathrm{Manx}_{40} \mathrm{~T}$ & 85 & 60 & 40 & 59.2 & 40.8 & 0.83 & $\begin{array}{c}16400 \\
(11600)\end{array}$ & $\begin{array}{c}40100 \\
(39800)\end{array}$ & $\begin{array}{c}2.4 \\
(3.4)\end{array}$ & 35.0 & 47.8 & 17.2 & 2.5 & 1.7 & 0.99 \\
\hline $\mathrm{PB}_{50} \mathrm{Manx}_{50} \mathrm{~T}$ & 88 & 50 & 50 & 49.0 & 51.0 & 0.77 & $\begin{array}{c}16300 \\
(10900)\end{array}$ & $\begin{array}{c}38900 \\
(38400)\end{array}$ & $\begin{array}{c}2.4 \\
(3.5)\end{array}$ & 23.1 & 48.4 & 28.5 & 2.0 & 2.2 & 0.97 \\
\hline PManxT & 85 & 0 & 100 & 0 & 100 & 0.51 & $\begin{array}{c}12900 \\
(8100)\end{array}$ & $\begin{array}{c}30200 \\
(29300)\end{array}$ & $\begin{array}{c}2.3 \\
(3.6)\end{array}$ & & & & & & \\
\hline
\end{tabular}

${ }^{a}$ Molar composition determined by integration of the ${ }^{1} \mathrm{H}$ NMR spectra. ${ }^{b}$ Intrinsic viscosity in $\mathrm{dL} \mathrm{g}{ }^{-1}$ measured in dichloroacetic acid at $25{ }^{\circ} \mathrm{C}$. ${ }^{c}$ Number- and weight-average molecular weights in $\mathrm{g} \mathrm{mol}^{-1}$ and dispersities measured by GPC in HFIP against PMMA standards after (without parentheses) and before purification (in parentheses). ${ }^{d}$ Randomness index of copolyesters statistically calculated on the basis of the ${ }^{13} \mathrm{C}$ NMR analysis.

weight-average molecular weights very close to those obtained for the precipitated product but with significantly higher dispersities. Such differences indicate the presence of minor amounts of oligomeric fractions or remaining monomers in the raw product that were then removed by precipitation. The ${ }^{1} \mathrm{H}$ NMR spectra corroborated the chemical structure of the copolyesters with all signals being correctly assigned to the different protons contained in their repeating units (Figure 2). Integration of the proton signals arising from B and Manx units led to quantify the composition of the copolyesters in such units. Data provided by this analysis are given in Table 1,
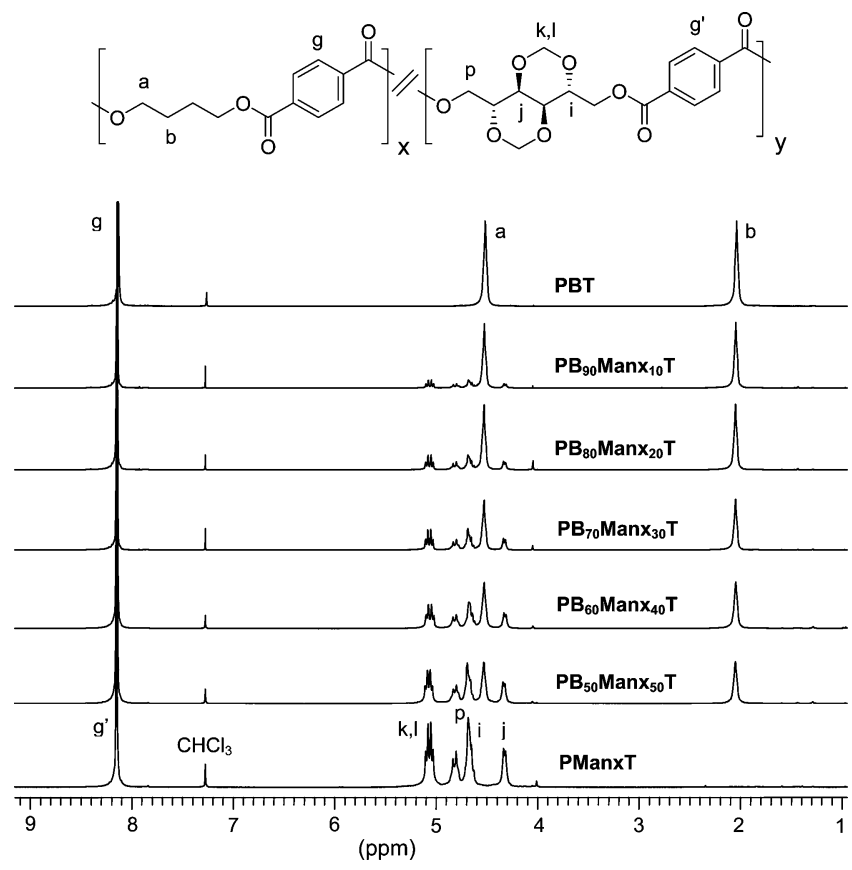

Figure 2. Compared ${ }^{1} \mathrm{H}$ NMR spectra of $\mathrm{PB}_{x} \mathrm{Manx}_{y} \mathrm{~T}$ copolyesters. showing that all copolyesters had compositions very close to those of their corresponding feeds.

The microstructure of $\mathrm{PB}_{x} \mathrm{Manx}_{y} \mathrm{~T}$ copolyesters was determined by ${ }^{13} \mathrm{C}$ NMR analysis. The signals of all the magnetically different carbons contained in the repeating units of the copolyesters appear well resolved in the ${ }^{13} \mathrm{C} N M R$ spectra (see Supporting Information) and in particular those arising from the nonprotonated aromatic carbons, which come out to be sensitive to sequence effects at the dyad level. As shown in Figure 3 for the whole set of $\mathrm{PB}_{x} \mathrm{Manx}_{y} \mathrm{~T}$ copolyesters, each resonance of the nonprotonated aromatic carbons appears split so that four peaks are seen in the 133$135 \mathrm{ppm}$ chemical shift interval corresponding to the three types of dyads (BB, BManx and ManxB, ManxManx) that are feasible along the copolyester chain. By integration of these peaks, the dyad contents, the number-average sequence lengths, and the degree of randomness were estimated (Table 1), leading to the conclusion that the microstructure of the copolyesters was at random in all cases.

Thermal Properties. 2,4:3,5-Di-O-methylene-D-mannitol is a thermally fairly stable solid compound which starts to volatilize above $150{ }^{\circ} \mathrm{C}$ and displays a sublimation temperature of $280{ }^{\circ} \mathrm{C}$ without perceivable decomposition. The thermal stability of PManxT homopolyester and $\mathrm{PB}_{x} \mathrm{Manx}_{y} \mathrm{~T}$ copolyesters made from this compound was evaluated by thermogravimetry under inert atmosphere and compared with that displayed by PBT. TGA traces are depicted in Figure 4, and thermal data provided by this analysis are presented in Table 2 . The weight loss profiles generated reveal that all polyesters start to decompose well above $360{ }^{\circ} \mathrm{C}$ with a thermal degradation mechanism involving one main step with the maximum rate at temperatures steadily increasing with the content in Manx units. The same trend is observed for ${ }^{\circ} T_{5 \%}$, and these results are in accordance with the high thermal stability observed for PManxT homopolyester, with ${ }^{\circ} T_{5 \%}$ and ${ }^{\max } T_{\mathrm{d}}$ at 378 and 421 ${ }^{\circ} \mathrm{C}$, respectively. The valuable conclusion drawn from this 

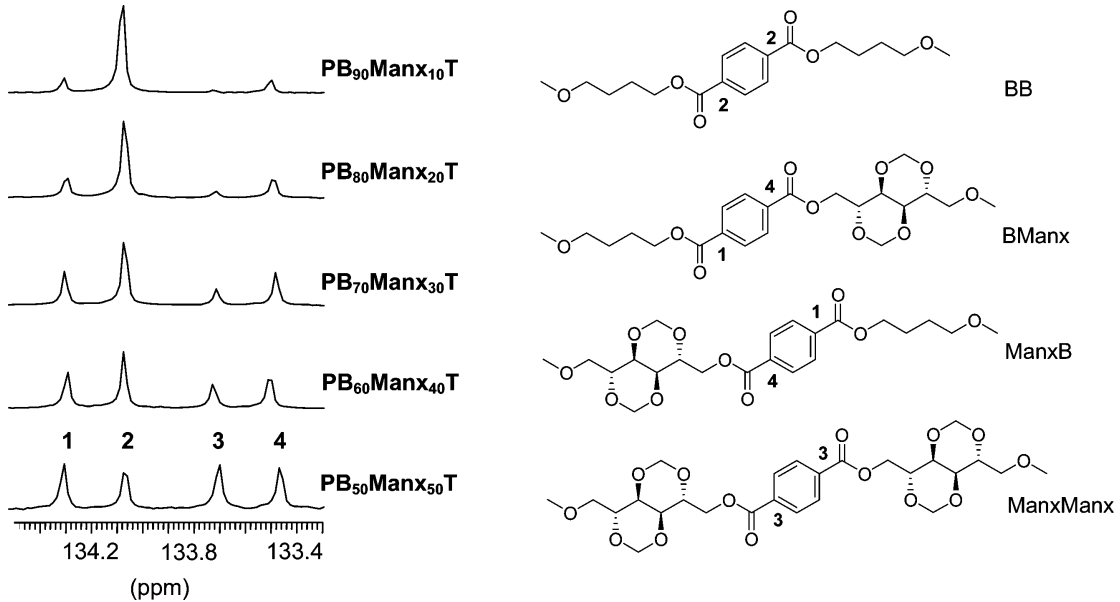

Figure 3. ${ }^{13} \mathrm{C}$ NMR signals used for the microstructure analysis of $\mathrm{PB}_{x} \mathrm{Manx}_{y} \mathrm{~T}$ copolyesters with indication of the dyads to which they are assigned.
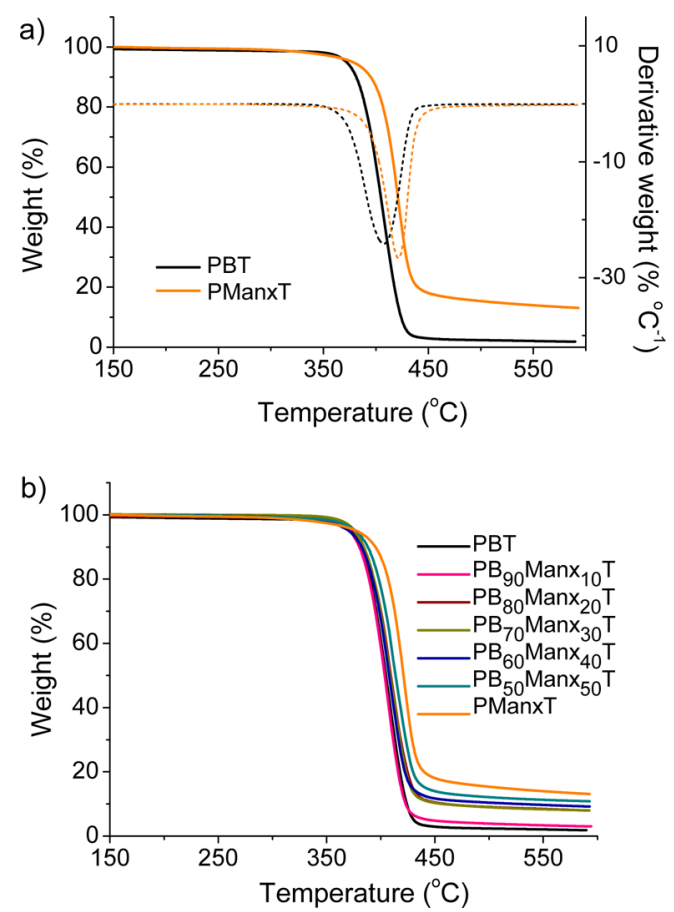

Figure 4. (a) TGA traces (solid lines) and derivative curves (dashed lines) of PBT and PManxT homopolyesters. (b) TGA traces of $\mathrm{PB}_{x} \mathrm{Manx}_{y} \mathrm{~T}$ copolyesters.

thermogravimetric study is that the insertion of Manx units in aromatic polyesters instead of reducing their thermal stability contributes to a significant increase in their decomposition temperatures. The fact of improving the thermal stability of commonly used aromatic polyesters such as PBT can broaden even more the application window of these materials.

Other thermal properties of prime importance in connection with the potential application of these copolyesters are the glass transition temperature $\left(T_{\mathrm{g}}\right)$ and the melting temperature $\left(T_{\mathrm{m}}\right)$. For instance, an increase in the $T_{\mathrm{g}}$ of these polyesters could open their use in the hot-filled and pasteurized-container fields. The glass transition temperatures of the PManxT and PBT homopolyesters and $\mathrm{PB}_{x} \mathrm{Manx} x \mathrm{~T}$ copolyesters were measured as the inflection point of the heating DSC traces of samples quenched from the melt (Figure 6a). A remarkable feature of PManxT homopolyester is that it has a $T_{\mathrm{g}}$ more than $100{ }^{\circ} \mathrm{C}$ higher than the aromatic PBT homopolyester. Regarding $\mathrm{PB}_{x} \mathrm{Manx}_{y} \mathrm{~T}$ copolyesters, their $T_{\mathrm{g}}$ increase steadily with the content in Manx units, with minimum and maximum values corresponding to their respective PBT and PManxT homopolyesters (Figure 5), as should be expected from their statistical microstructure. As expected from its cyclic stiff nature, the effect of Manx on $T_{\mathrm{g}}$ of PBT is largely greater than that exerted by the incorporation of acyclic sugar units such as trimethoxy xylitol or L-arabinitol. ${ }^{31}$ It has even a much more pronounced effect than 2,3:4,5-di-O-methylene-galactitol, another acetalized sugar diol constituted by two nonfused dioxolane rings, which has been recently reported by us as capable of raising the $T_{\mathrm{g}}$ of PBT by near $30^{\circ} \mathrm{C}$ when it replaces 1,4-butanediol in a $40 \%{ }^{20}$ The effect of Manx turns to be similar to that of isosorbide; in fact, both PBT copolyesters containing $40 \%$ of either Manx or isosorbide ${ }^{14,16}$ display a $T_{\mathrm{g}}$ of around $90{ }^{\circ} \mathrm{C}$. No doubt the fused bicyclic structure characteristic of both Manx and isosorbide is unique in providing the polyester chain with a degree of stiffness not achievable with the insertion of rotable bicyclic units, as it is the case of the acetalized hexitol with galacto configuration.

DSC traces of polyesters in the powdered form registered at first heating are depicted in Figure $6 \mathrm{~b} . \mathrm{PB}_{x} \mathrm{Manx}_{y} \mathrm{~T}$ copolyesters with molar contents in Manx below or equal to $40 \%$, as well as PBT homopolyester, gave heating traces with melting endotherms indicating that they are semicrystalline. Comparison of melting temperatures and enthalpies of semicrystalline $\mathrm{PB}_{x} \mathrm{Manx}_{y} \mathrm{~T}$ copolyesters with that of PBT homopolyester leads to the conclusion that the insertion of Manx units gives place to a significant decrease in both $T_{\mathrm{m}}$ and $\Delta H_{\mathrm{m}}$ (Table 2). $\mathrm{PB}_{50} \mathrm{Manx}_{50} \mathrm{~T}$ copolyester and PManxT homopolyester appear to be amorphous. DSC data recorded from polyester films prepared by casting from solution are not far from those obtained from powders, the higher coincidence being found for lower contents in Manx units.

Isothermal Crystallization. The cooling DSC traces obtained from molten samples revealed that $\mathrm{PB}_{x} \mathrm{Manx}_{y} \mathrm{~T}$ copolyesters with molar contents in Manx below or equal to $20 \%$, as well as PBT homopolyester were able to crystallize from the melt. After crystallization from the melt, these polyesters recovered about $75-95 \%$ of their initial crystallinity and displayed almost the same melting temperatures. Given the relevance of this property regarding polymer processing, the isothermal crystallization of $\mathrm{PB}_{90} \mathrm{Manx}_{10} \mathrm{~T}$ and $\mathrm{PB}_{80} \mathrm{Manx}_{20} \mathrm{~T}$ 
Table 2. Thermal Properties of $\mathrm{PB}_{x} \mathrm{Manx} \mathrm{y}_{y} \mathrm{~T}$ Copolyesters

\begin{tabular}{|c|c|c|c|c|c|c|c|c|c|c|}
\hline \multirow[b]{3}{*}{ copolyester } & \multicolumn{3}{|c|}{ TGA } & \multicolumn{7}{|c|}{ DSC } \\
\hline & \multirow[b]{2}{*}{${ }^{\circ} T_{5 \%}{ }^{a}\left({ }^{\circ} \mathrm{C}\right)$} & \multirow[b]{2}{*}{$T_{\mathrm{d}}^{b}\left({ }^{\circ} \mathrm{C}\right)$} & \multirow[b]{2}{*}{$W^{c}(\%)$} & \multirow[b]{2}{*}{$T_{\mathrm{g}}^{d}\left({ }^{\circ} \mathrm{C}\right)$} & \multicolumn{2}{|c|}{ first heating ${ }^{e}$} & \multicolumn{2}{|c|}{ cooling $^{e}$} & \multicolumn{2}{|c|}{ second heating $^{e}$} \\
\hline & & & & & $T_{\mathrm{m}}\left({ }^{\circ} \mathrm{C}\right)$ & $\Delta H_{\mathrm{m}}\left(\mathrm{J} \mathrm{g}^{-1}\right)$ & $T_{\mathrm{c}}\left({ }^{\circ} \mathrm{C}\right)$ & $\Delta H_{\mathrm{c}}\left(\mathrm{J} \mathrm{g}^{-1}\right)$ & $T_{\mathrm{m}}\left({ }^{\circ} \mathrm{C}\right)$ & $\Delta H_{\mathrm{m}}\left(\mathrm{J} \mathrm{g}^{-1}\right)$ \\
\hline PBT & 371 & 408 & 2 & 31 & $\begin{array}{c}223 \\
(223)\end{array}$ & $\begin{array}{c}56.2 \\
(54.3)\end{array}$ & 196 & 43.3 & 223 & 44.0 \\
\hline $\mathrm{PB}_{90} \mathrm{Manx}_{10} \mathrm{~T}$ & 371 & 408 & 3 & 55 & $\begin{array}{c}197 \\
(196)\end{array}$ & $\begin{array}{c}34.1 \\
(33.0)\end{array}$ & 159 & 30.4 & 198 & 31.3 \\
\hline $\mathrm{PB}_{80} \mathrm{Manx}_{20} \mathrm{~T}$ & 372 & 410 & 8 & 66 & $\begin{array}{c}184 \\
(183)\end{array}$ & $\begin{array}{c}26.0 \\
(27.0)\end{array}$ & 140 & 23.4 & 184 & 24.1 \\
\hline $\mathrm{PB}_{70} \mathrm{Manx}_{30} \mathrm{~T}$ & 374 & 411 & 8 & 77 & $\begin{array}{c}162 \\
(162)\end{array}$ & $\begin{array}{c}5.5 \\
(16.6)\end{array}$ & & & & \\
\hline $\mathrm{PB}_{60} \mathrm{Manx}_{40} \mathrm{~T}$ & 376 & 411 & 9 & 88 & $\begin{array}{c}122 \\
(119)\end{array}$ & $\begin{array}{c}5.0 \\
(9.8)\end{array}$ & & & & \\
\hline $\mathrm{PB}_{50} \mathrm{Manx}_{50} \mathrm{~T}$ & 377 & 412 & 11 & 100 & & & & & & \\
\hline PManxT & 378 & 421 & 13 & 137 & & & & & & \\
\hline
\end{tabular}

${ }^{a}$ Temperature at which $5 \%$ weight loss was observed. ${ }^{b}$ Temperature for maximum degradation rate. ${ }^{c}$ Remaining weight at $600{ }^{\circ} \mathrm{C} .{ }^{d} \mathrm{Glass}$-transition temperature taken as the inflection point of the heating DSC traces of melt-quenched samples recorded at $20{ }^{\circ} \mathrm{C} \mathrm{min}{ }^{-1}$. ${ }^{e} \mathrm{Melting}\left(T_{\mathrm{m}}\right)$ and crystallization $\left(T_{\mathrm{c}}\right)$ temperatures and melting $\left(\Delta H_{\mathrm{m}}\right)$ and crystallization $\left(\Delta H_{\mathrm{c}}\right)$ enthalpies measured by DSC at heating $/$ cooling rates of $10^{\circ} \mathrm{C}$ min ${ }^{-1}$ of precipitated samples (without parentheses) and of films (in parentheses).

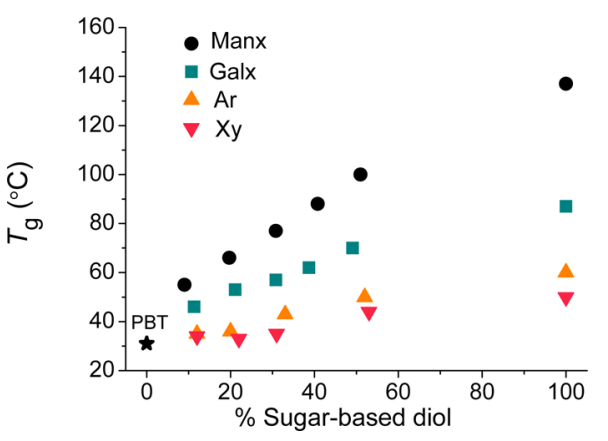

Figure 5. Glass-transition temperature versus composition plot for PBT copolyesters containing 2,4:3,5-di-O-methylene-D-mannitol (Manx), 2,3:4,5-di-O-methylene-galactitol (Galx) ${ }^{20}{ }^{2,3,4-t r i-O-m e t h-~}$ yl-L-arabinitol (Ar), or 2,3,4-tri-O-methylxylitol (Xy). ${ }^{31}$

copolyesters and PBT homopolyester was comparatively studied in the $150-210{ }^{\circ} \mathrm{C}$ interval. Unfortunately, not all of them could be compared at exactly the same isothermal crystallization temperature due to the large differences in crystallization rates displayed by them and to the short ranges of temperature in which crystallization evolution is measurable by DSC. Nevertheless, crystallization conditions were chosen as close as possible in order to be able to draw out meaningful conclusions. The Hoffman-Weeks plot of $T_{\mathrm{m}}$ versus $T_{\mathrm{c}}$ showed a good correlation (see Supporting Information) and provided the equilibrium melting temperatures, which, as expected, continue to display the same trend with composition as was observed for the $T_{\mathrm{m}}$ measured for nonisothermally crystallized samples.

Kinetic data afforded by the Avrami analysis of the results obtained at the selected crystallization temperatures are gathered in Table 3. The evolution of the relative crystallinity, $X_{\mathcal{c}}$, with crystallization time and the corresponding Avrami data plots $\log \left[-\ln \left(1-X_{c}\right)\right]$ versus $\log \left(t-t_{0}\right)$ for some illustrative crystallization experiments are depicted in Figure 7. The morphological appearance of the crystallized material observed by polarized optical microscopy is shown in the Supporting Information. It is seen that for each polyester the crystallization half-time as well as the Avrami exponent $n$ increase with
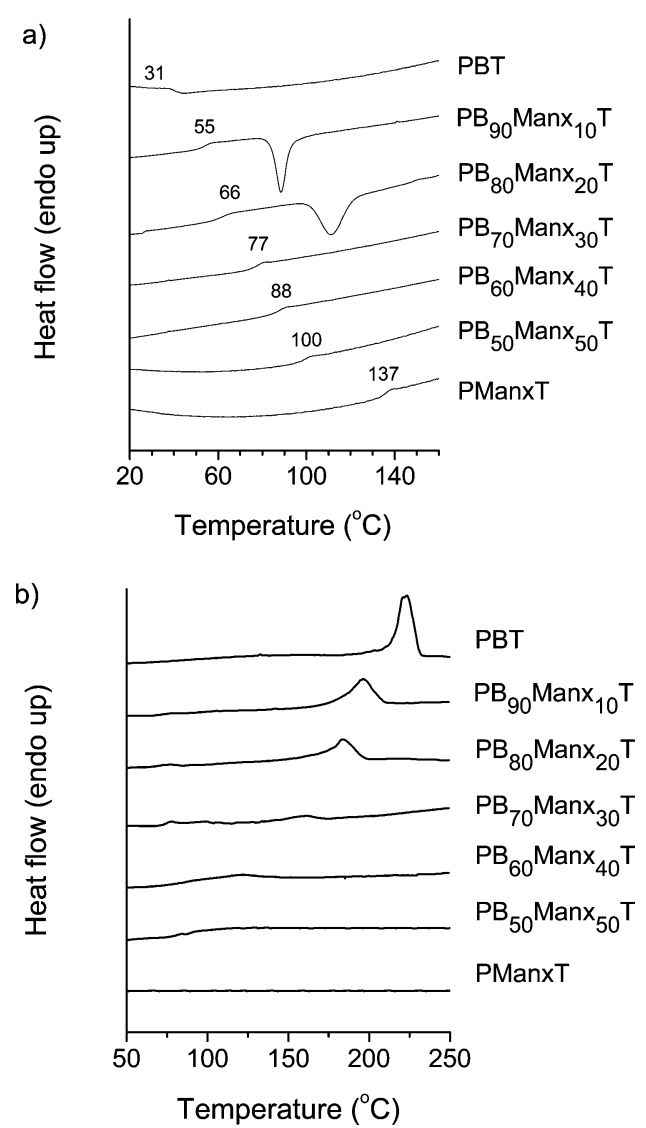

Figure 6. (a) DSC heating traces of $\mathrm{PB}_{x} \mathrm{Manx}_{y} \mathrm{~T}$ copolyesters quenched from the melt. (b) DSC melting traces of the $\mathrm{PB}_{x}$ Manx $x_{y} \mathrm{~T}$ copolyesters without being subjected to any thermal treatment.

temperature, the values of the latter being in the 2.0-2.6 range corresponding to a complex axialitic-spherulitic crystallization as was observed by polarizing optical microscopy. The doublelogarithmic plot indicates that only primary crystallization takes place in the selected time intervals and that the presence of Manx units depresses the crystallizability in terephthalate copolyesters. The valuable conclusion that can be drawn from 
Table 3. Isothermal Crystallization Data of $\mathrm{PB}_{x} \mathrm{Manx} y$ Copolyesters

\begin{tabular}{lccrcrc} 
copolyester & $\begin{array}{c}T_{\mathrm{c}} \\
\left({ }^{\circ} \mathrm{C}\right)\end{array}$ & $\begin{array}{c}t_{0} \\
(\mathrm{~min})\end{array}$ & $\begin{array}{c}t_{1 / 2} \\
(\mathrm{~min})\end{array}$ & $n$ & $-\log k$ & $\begin{array}{c}T_{\mathrm{m}} \\
\left({ }^{\circ} \mathrm{C}\right)\end{array}$ \\
\hline $\mathrm{PBT}$ & 200 & 0.19 & 0.82 & 2.14 & -0.25 & 223.9 \\
& 205 & 0.51 & 2.68 & 2.45 & 1.02 & 225.5 \\
& 210 & 2.33 & 12.83 & 2.56 & 2.78 & 226.9 \\
$\mathrm{~PB}_{90} \mathrm{Manx}_{10} \mathrm{~T}$ & 165 & 0.15 & 1.13 & 2.01 & 0.15 & 194.5 \\
& 170 & 0.26 & 2.14 & 2.12 & 0.75 & 196.3 \\
& 175 & 0.31 & 4.37 & 2.43 & 1.64 & 198.0 \\
& 180 & 0.59 & 8.53 & 2.52 & 2.42 & 199.8 \\
& 185 & 1.93 & 19.43 & 2.57 & 3.34 & 202.1 \\
$\mathrm{~PB}_{80} \mathrm{Manx}_{20} \mathrm{~T}$ & 150 & 0.19 & 1.61 & 2.02 & 0.56 & 184.1 \\
& 155 & 0.23 & 2.45 & 2.04 & 0.93 & 185.3 \\
& 160 & 0.29 & 3.50 & 2.07 & 1.26 & 186.9 \\
& 165 & 0.44 & 5.60 & 2.13 & 1.74 & 188.8 \\
& 170 & 0.98 & 11.85 & 2.20 & 2.46 & 190.5 \\
\hline
\end{tabular}
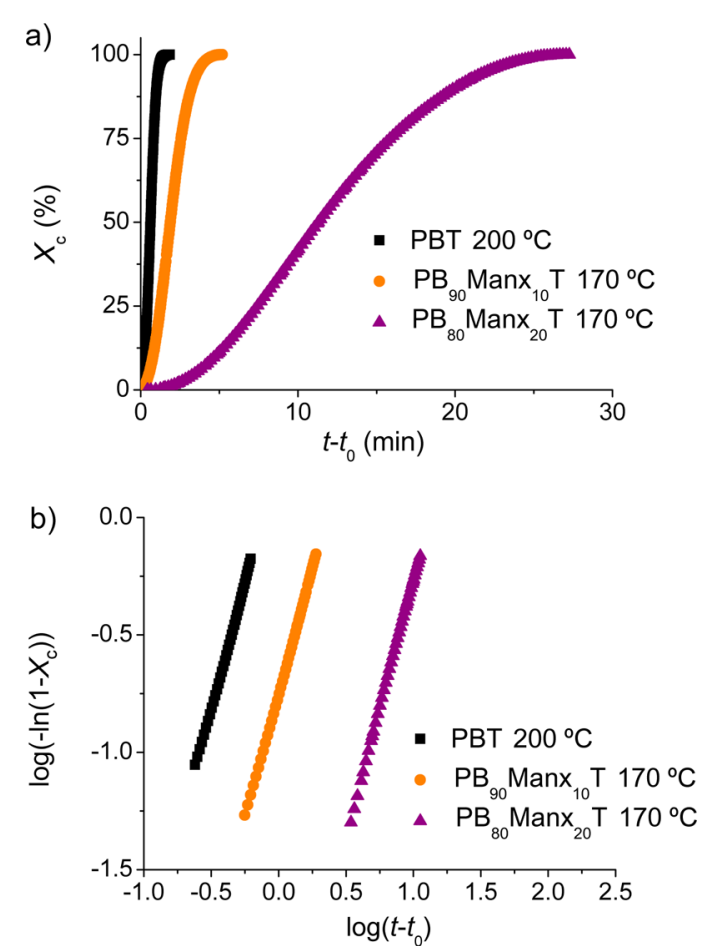

Figure 7. Isothermal crystallization of $\mathrm{PBT}, \mathrm{PB}_{90} \mathrm{Manx}_{10} \mathrm{~T}$, and $\mathrm{PB}_{80} \mathrm{Manx}_{20} \mathrm{~T}$ at the indicated temperatures. Relative crystallinity versus time plot (a) and log-log plot (b).

this study is that $\mathrm{PB}_{90} \mathrm{Manx}_{10} \mathrm{~T}$ and $\mathrm{PB}_{80} \mathrm{Manx}_{20} \mathrm{~T}$ copolyesters continue displaying the ability of crystallizing from the melt as their parent homopolyester PBT although at lower crystallization rates.

Crystal Structure and Stress-Strain Behavior. Powder $\mathrm{X}$-ray diffraction analyses were performed for all $\mathrm{PB}_{x} \mathrm{Manx}_{y} \mathrm{~T}$ copolyesters as well as PManxT and PBT homopolyesters. Powder X-ray diffraction profiles are presented in Figure 8a, and Bragg spacings present in such patterns are listed in Table 4. In agreement with DSC results, copolyesters containing up to $40 \%$ of Manx produced discrete diffraction scattering distinctive of semicrystalline material, whereas fully plain profiles characteristic of amorphous material were obtained from $\mathrm{PB}_{50} \mathrm{Manx}_{50} \mathrm{~T}$ as well as from the PManxT homopolyester. The PBT pattern is characterized by five prominent reflections at 5.6, 5.1, 4.3, 3.8, and 3.6 A. Essentially the same pattern
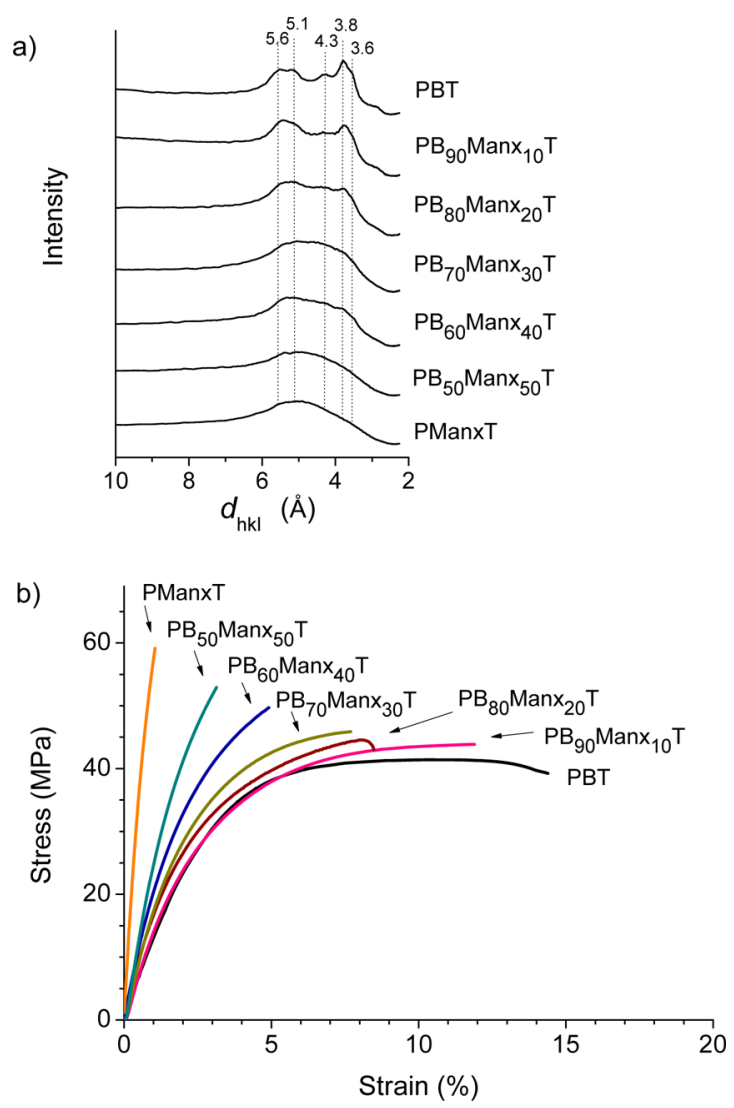

Figure 8. Powder WAXS profiles (a) and stress-strain curves (b) of $\mathrm{PB}_{x} \mathrm{Manx}_{y} \mathrm{~T}$ copolyesters.

regarding both spacing and relative intensities is shared by $\mathrm{PB}_{x} \mathrm{Manx}_{y} \mathrm{~T}$ copolyesters with low content in Manx, revealing that the triclinic crystal structure of $\mathrm{PBT}^{32}$ must be retained in polyesters. The crystallinity index was estimated as the quotient between crystalline area and total area of the X-ray diffraction pattern, showing that $\mathrm{PB}_{90} \mathrm{Manx}_{10} \mathrm{~T}, \mathrm{~PB}_{80} \mathrm{Manx}_{20} \mathrm{~T}$, $\mathrm{PB}_{70} \mathrm{Manx}_{30} \mathrm{~T}$, and $\mathrm{PB}_{60} \mathrm{Manx}_{40} \mathrm{~T}$ were semicrystalline with crystalline indexes decreasing for increasing contents in Manx units. However, $\mathrm{PB}_{50} \mathrm{Manx}_{50} \mathrm{~T}$ copolyester and PManxT copolyester did not show any discrete reflection characteristic of crystalline material. These X-ray diffraction results are in full agreement with DSC results and confirmed that $\mathrm{PB}_{x} \mathrm{Manx}_{y} \mathrm{~T}$ copolyesters with molar contents in Manx below or equal to $40 \%$ are semicrystalline.

To evaluate the influence of the presence of Manx in the mechanical properties of copolyesters, tensile assays of PManxT copolyester as well as $\mathrm{PB}_{x} \mathrm{Manx}_{y} \mathrm{~T}$ copolyesters were carried out using the films that were prepared by casting as described in the Experimental Section. For comparison purposes, mechanical properties of PBT were also tested. According to enthalpy values (Table 2), the degree of crystallinity of these films must be close to that displayed by powders with $X_{c}$ steadily decreasing with the increasing content of the copolyester in Manx units to become 0 for $\mathrm{PB}_{50} \mathrm{Manx}_{50} \mathrm{~T}$ and PManxT (Table 4). The stress-strain curves resulting from tensile essays are depicted in Figure $8 \mathrm{~b}$, and the mechanical parameters measured in these tests are compared in Table 4. PManxT homopolyester displayed higher elastic modulus and tensile strength than PBT, and accordingly $\mathrm{PB}_{x} \mathrm{Manx}_{y} \mathrm{~T}$ copolyesters present a nearly steady trend consisting of a continuous increase in both elastic modulus and tensile strength and a decrease in ductility when 
Table 4. Powder X-ray Diffraction Data and Mechanical Properties of $\mathrm{PB}_{x} \mathrm{Manx} \mathrm{T}_{y} \mathrm{~T}$ Copolyesters

\begin{tabular}{|c|c|c|c|c|c|c|c|c|c|}
\hline \multirow[b]{2}{*}{ copolyester } & \multicolumn{6}{|c|}{$\mathrm{X}$-ray diffraction data } & \multicolumn{3}{|c|}{ mechanical properties } \\
\hline & & & $d^{a}(\AA)$ & & & $X_{c}^{b}$ & elastic modulus (MPa) & tensile strength $(\mathrm{MPa})$ & elongation at break (\%) \\
\hline PBT & $5.6 \mathrm{~s}$ & $5.1 \mathrm{~s}$ & $4.3 \mathrm{~s}$ & $3.8 \mathrm{~s}$ & $3.6 \mathrm{~m}$ & 0.48 & $841 \pm 15$ & $42 \pm 5$ & $14 \pm 3$ \\
\hline $\mathrm{PB}_{90} \mathrm{Manx}_{10} \mathrm{~T}$ & $5.6 \mathrm{~s}$ & $5.1 \mathrm{~s}$ & $4.3 \mathrm{~m}$ & $3.8 \mathrm{~s}$ & $3.6 \mathrm{~m}$ & 0.39 & $852 \pm 13$ & $44 \pm 6$ & $12 \pm 3$ \\
\hline $\mathrm{PB}_{80} \mathrm{Manx}_{20} \mathrm{~T}$ & $5.6 \mathrm{~m}$ & $5.1 \mathrm{~m}$ & $4.3 \mathrm{~m}$ & $3.8 \mathrm{~m}$ & $3.6 \mathrm{w}$ & 0.32 & $871 \pm 25$ & $45 \pm 7$ & $9 \pm 2$ \\
\hline $\mathrm{PB}_{70} \mathrm{Manx}_{30} \mathrm{~T}$ & $5.6 \mathrm{w}$ & $5.1 \mathrm{w}$ & $4.3 \mathrm{w}$ & $3.8 \mathrm{w}$ & $3.6 \mathrm{w}$ & 0.11 & $888 \pm 17$ & $46 \pm 5$ & $8 \pm 3$ \\
\hline $\mathrm{PB}_{60} \mathrm{Manx}_{40} \mathrm{~T}$ & $5.6 \mathrm{w}$ & $5.1 \mathrm{w}$ & $4.3 \mathrm{w}$ & $3.8 \mathrm{w}$ & $3.6 \mathrm{w}$ & 0.10 & $891 \pm 19$ & $50 \pm 7$ & $5 \pm 2$ \\
\hline $\mathrm{PB}_{50} \mathrm{Manx}_{50} \mathrm{~T}$ & & & & & & 0 & $909 \pm 26$ & $52 \pm 5$ & $3 \pm 1$ \\
\hline PManxT & & & & & & 0 & $1067 \pm 29$ & $59 \pm 6$ & $2 \pm 1$ \\
\hline
\end{tabular}

${ }^{a}$ Bragg spacings measured in powder diffraction patterns for samples coming directly from synthesis. Intensities visually estimated as follows: $\mathrm{m}$, medium; s, strong; w, weak. ${ }^{b}$ Crystallinity index calculated as the quotient between crystalline area and total area. Crystalline and amorphous areas in the X-ray diffraction pattern were quantified using PeakFit v4.12 software.

their content in Manx units increases. The observed variations in the stress-strain behavior are fully consistent with the changes in $T_{\mathrm{g}}$. Apparently, the mechanical moduli of these copolyesters are mainly determined by the mobility of the chains in the amorphous phase rather than by the structural stiffness induced by the presence of crystalline domains.

\section{CONCLUSIONS}

For the first time, polyesters from the biobased 2,4:3,5-di-Omethylene-D-mannitol monomer, obtained by internal acetalization of the secondary hydroxyl groups of D-mannitol, have been successfully synthesized. By taking special care of polycondensation conditions, polyesters and statistical copolyesters with pretty high molecular weights were obtained in good yields. The incorporation of the sugar derived diol improved appreciably the thermal stability of the resulting polyesters. The most remarkable effect of copolymerization was however noticed on the glass-transition temperature which increased with the content in 2,4:3,5-di-O-methylene-Dmannitol almost linearly with a slope of about of $1{ }^{\circ} \mathrm{C} / \%$ mol, allowing fine-tuning of $T_{\mathrm{g}}$ of PBT over a wide range. Consequently, the mechanical moduli of the copolyesters also increased significantly in the same sense. Although copolymerization depressed the crystallinity and crystallizability of PBT, those copolyesters containing up to $40 \%$ of sugar based units were semicrystalline and adopted the crystal structure of PBT, and those containing up to $20 \%$ were able to crystallize from the melt. The 50/50 copolyester and the polyester entirely made of Manx units were amorphous, at least under the crystallization conditions used in this work. The bicyclic sugarbased diol investigated in this work as monomer for polycondensation stands out not only for being a sustainable compound but also for providing polyesters with satisfactory molecular weights and with improved thermal and mechanical properties; nevertheless, the synthesis of this compound will need to be improved in order to make it simpler and to avoid the use of environmentally unfriendly reagents.

\section{ASSOCIATED CONTENT}

\section{S Supporting Information}

Additional figures (Figures 1-7). This material is available free of charge via the Internet at http://pubs.acs.org.

\section{AUTHOR INFORMATION}

\section{Corresponding Author}

*E-mail sebastian.munoz@upc.edu.

\section{Notes}

The authors declare no competing financial interest.

\section{ACKNOWLEDGMENTS}

Financial support for this work was provided by MICINN (Spain) with Grant MAT2009-14053-C02 and by AGAUR (Catalonia) with Grant 2009SGR1469. The authors are also indebted to MEC (Spain) for the FPU grant awarded to Cristina Lavilla.

\section{REFERENCES}

(1) Wool, R; Sun, S. Biobased Polymers and Composites; Academic Press: New York, 2005.

(2) Pillai, C. K. S. Des. Monomers Polym. 2010, 13, 87-121.

(3) Gandini, A. Green Chem. 2011, 13, 1061-1083.

(4) Chen, G. Q.; Patel, M. K. Chem. Rev. 2012, 112, 2082-2099.

(5) Kiely, D. E.; Chen, L.; Lin, T. H. J. Am. Chem. Soc. 1994, 116, 571-578.

(6) Kiely, D. E.; Chen, L.; Lin, T. H. J. Polym. Sci., Polym. Chem. 2000, 38, 594-603.

(7) Okada, M. Prog. Polym. Sci. 2002, 27, 87-133.

(8) Metzke, M.; Guan, Z. Biomacromolecules 2008, 9, 208-215.

(9) Williams, C. K. Chem. Soc. Rev. 2007, 36, 1573-1580.

(10) Kricheldorf, H. R. J. Macromol. Sci. 1997, C37, 599-631.

(11) Gandini, A.; Coelho, D.; Gomes, M.; Reis, B.; Silvestre, A. J. D. J. Mater. Chem. 2009, 19, 8656-8664.

(12) Gomes, M.; Gandini, A.; Silvestre, A. J. D.; Reis, B. J. Polym. Sci., Polym. Chem. 2011, 49, 3759-3768.

(13) Fenouillot, F.; Rousseau, A.; Colomines, G.; Saint-Loup, R; Pascault, J. P. Prog. Polym. Sci. 2010, 35, 578-622.

(14) Sablong, R.; Duchateau, R.; Koning, C. E.; de Wit, G.; van Es, D.; Koelewijn, R.; van Haveren, J. Biomacromolecules 2008, 9, 30903097.

(15) Wu, J.; Eduard, P.; Thiyagarajan, S.; Jasinska-Walc, L.; Rozanski, A.; Fonseca Guerra, C.; Noordover, B. A. J.; van Haveren, J.; van Es, D. S.; Koning, C. E. Macromolecules 2012, 45, 5069-5080.

(16) Kricheldorf, H. R.; Behnken, G.; Sell, M. J. Macromol. Sci., Pure Appl. Chem. 2007, 44, 679-684.

(17) Storbeck, R.; Ballauff, M. J. Appl. Polym. Sci. 1996, 59, 11991202.

(18) Lavilla, C.; Alla, A.; Martínez de Ilarduya, A.; Benito, E.; GarcíaMartín, M. G.; Galbis, J. A.; Muñoz-Guerra, S. Biomacromolecules 2011, $12,2642-2652$.

(19) Lavilla, C.; Alla, A.; Martínez de Ilarduya, A.; Benito, E.; GarcíaMartín, M. G.; Galbis, J. A.; Muñoz-Guerra, S. J. Polym. Sci., Polym. Chem 2012, 50, 1591-1604.

(20) Lavilla, C.; Alla, A.; Martínez de Ilarduya, A.; Benito, E.; GarcíaMartín, M. G.; Galbis, J. A.; Muñoz-Guerra. Polymer 2012, 53, 34323445.

(21) Gallucci, R. R; Patel, B. R. Poly(Butylene Terephthalate). In Scheirs, J., Long, T. E., Eds.; Modern Polyesters, Chemistry and 
Technology of Polyesters and Copolyesters; John Wiley \& Sons: Chichester, 2004; pp 293-321.

(22) Tripathy, A. R.; MacKnight, W. J.; Kukureka, S. N. Macromolecules 2004, 37, 6793-6800.

(23) Brigl, P.; Gruner, H. Ber 1932, 65B, 641-645.

(24) Haworth, W. N.; Wiggins, L. F. J. Chem. Soc. 1944, 58-61.

(25) Haskins, W. T.; Hann, R. M.; Hudson, C. S. J. Am. Chem. Soc. 1943, 65, 67-70.

(26) Burden, I. J.; Stoddart, J. F. J. Chem. Soc., Perkin Trans. 1 1975, 7, 666-674.

(27) Mills, J. A. Adv. Carbohydr. Chem. 1955, 10, 1-53.

(28) Franks, F.; Dadok, J.; Ying, S.; Kay, R. L.; Grigera, J. R. J. Chem. Soc., Faraday Trans. 1991, 87, 579-585.

(29) Jardetzky, O.; Roberts, G. C. K. Molecular Biology; Academic Press: New York, 1981; p 201.

(30) Bernstein, J.; Green, B. S.; Rejtö, M. J. Am. Chem. Soc. 1980, 102, 323-328.

(31) Alla, A.; Hakkou, K.; Zamora, F.; Martínez de Ilarduya, A.; Galbis, J. A.; Muñoz-Guerra, S. Macromolecules 2006, 39, 1410-1416.

(32) Hall, I. H. The determination of the structures of aromatic polyesters from their wide-angle X-ray diffraction patterns. In Hall, I. H., Ed.; Structure of Crystalline Polymers; Elselvier Applied Science: London, 1984; pp 39-78. 